\title{
Surveying graduate students' attitudes and approaches to problem solving
}

\author{
Andrew Mason and Chandralekha Singh \\ Department of Physics and Astronomy, University of Pittsburgh, Pittsburgh, Pennsylvania 15260, USA
}

(Received 10 May 2010; published 1 December 2010)

\begin{abstract}
Students' attitudes and approaches to problem solving in physics can profoundly influence their motivation to learn and development of expertise. We developed and validated an Attitudes and Approaches to Problem Solving survey by expanding the Attitudes toward Problem Solving survey of Marx and Cummings and administered it to physics graduate students. Comparison of their responses to the survey questions about problem solving in their own graduate-level courses vs problem solving in the introductory physics courses provides insight into their expertise in introductory and graduate-level physics. The physics graduate students' responses to the survey questions were also compared with those of introductory physics and astronomy students and physics faculty. We find that, even for problem solving in introductory physics, graduate students' responses to some survey questions are less expertlike than those of the physics faculty. Comparison of survey responses of graduate students and introductory students for problem solving in introductory physics suggests that graduate students' responses are in general more expertlike than those of introductory students. However, survey responses suggest that graduate-level problem solving by graduate students on several measures has remarkably similar trends to introductory-level problem solving by introductory students.
\end{abstract}

DOI: 10.1103/PhysRevSTPER.6.020124

PACS number(s): 01.40.G-, 01.40.Ha

\section{INTRODUCTION}

Students' attitudes and approaches toward learning can have a significant impact on what students actually learn [1-6]. Mastering physics amounts to not only developing a robust knowledge structure of physics concepts but also developing productive attitudes about the knowledge and learning in physics. In essence, it is impossible to become a true physics expert without a simultaneous evolution of expertlike attitudes about the knowledge and learning in physics. If students think that physics is a collection of disconnected facts and formulas rather than seeing the coherent structure of the knowledge in physics, they are unlikely to see the need for organizing their knowledge hierarchically. Similarly, if students believe that only a few smart people can do physics, the teacher is the authority and the students' task in a physics course is to take notes, memorize the content and reproduce it on the exam and then forget it, they are unlikely to make an effort to synthesize and analyze what is taught, ask questions about how concepts fit together or how they can extend their knowledge beyond what is taught. Similarly, if students believe that if they cannot solve a problem within $10 \mathrm{~min}$, they should give up, they are unlikely to persevere and make an effort to explore strategies for solving challenging problems.

The Maryland Physics Expectation Survey (MPEX) was developed to explore students' attitudes and expectations related to physics [4]. When the survey was administered before and after instruction in various introductory physics courses, it was found that students' attitudes about physics after instruction deteriorated compared to their expectations before taking introductory physics. Very few carefully designed courses and curricula have shown major improvements in students' expectations after an introductory physics course [7-9].

Colorado Attitudes about Science Survey (CLASS) is another survey which is similar to the MPEX survey and ex- plores students' attitudes about physics [5,6]. The analysis of CLASS data yields qualitatively similar results to those obtained using the MPEX survey. Moreover, when introductory physics students were asked to answer the survey questions twice, once providing the answers from their perspective and then from the perspective of their professors, introductory students' responses to many questions were very different from their perspective compared to what they claimed would be their professors' perspective [6]. Thus, introductory students maintained their views although they knew that the physics professors would have different views about some of the survey questions.

Cummings et al. [7,10] developed an Attitudes toward Problem Solving Survey (APSS) which is partially based upon the Maryland Physics Expectations Survey (MPEX). The original APSS survey has 20 questions and examines students' attitudes toward physics problem solving [10]. The survey was given to students before and after instruction at three types of institutions: a large university, a smaller university and a college. It was found that students' attitudes about problem solving did not improve after instruction (deteriorated slightly) at the large University and the attitudes were least expertlike (least favorable) at the large University with a large class size.

Students' attitudes and approaches to learning and problem solving can affect how they learn and how much time they spend repairing, extending and organizing their knowledge structure. If instructors are aware of students' attitudes and approaches to problem solving, they can explicitly exploit strategies to improve them. For example, knowing students' beliefs about mathematics learning (which is similar to students' beliefs about physics learning in many aspects) motivated Schoenfeld to develop a curriculum to improve students' attitude [11-14]. In particular, based on the knowledge that students in the introductory mathematics courses often start looking for formulas right away while solving a mathematics problem instead of performing a careful conceptual analysis and planning, Schoenfeld used an explicit strategy 
to change students' approach. He routinely placed students in small groups and asked them to solve problems. He would move around and ask them questions such as "What are you doing? Why are you doing it? How does it take you closer to your goals?" Very soon, students who were used to immediately looking for formulas were embarrassed and realized that they should first perform conceptual analysis and planning before jumping into the implementation of the problem solution. Schoenfeld's strategy helped most students adopt an effective problem solving approach within a few weeks and they started to devote time to qualitative analysis and decision making before looking for equations [11].

Another unfavorable attitude about mathematical problem solving that Schoenfeld wanted students to give up was that students often felt that if they could not solve a problem within 5-10 min, they should give up [11-14]. Schoenfeld realized that one reason students had such an attitude was because they saw their instructor solving problems during the lectures without faltering or spending too much time thinking. To bust this myth about problem solving, Schoenfeld began each of his geometry classes with the first $10 \mathrm{~min}$ devoted to taking students' questions about challenging geometry problems (often from the end of the chapter exercises) and thus attempting to solve them without prior preparation. Students discovered that Schoenfeld often struggled with the problems and was unable to solve them in the first 10 min and asked students to continue to think about the problems until one of them had solved it and shared it with others. This approach improved students' attitude and their self-confidence in solving mathematics problems.

Here, we briefly discuss the development, validation and administration of the Attitudes and Approaches to Problem Solving (AAPS) survey, a modified version of APSS survey [10], that includes additional questions related to approaches to problem solving and we focus on the responses of physics graduate students [15]. We explore how graduate students differ in their attitudes and approaches while they solve graduate-level problems versus introductory-level problems. The survey questions were administered in the form of statements that one could agree or disagree with on a scale of 1 (strongly agree) to 5 (strongly disagree) with 3 signifying a neutral response. We do not differentiate between "agree" and "strongly agree" in interpreting the data (both are coded as +1). Similarly, "disagree" and "strongly disagree" were combined (both are coded as -1) for streamlining the data and their interpretation. A favorable response refers to either "agree" or "disagree" based upon which one was favored by a majority of physics faculty. We find that, on some measures, graduate students have very different attitudes and approaches about solving introductory physics problems compared to their own graduate-level problems. The attitudes and approaches of graduate students on the AAPS survey was also compared to those of introductory physics and astronomy students and to physics faculty. We find that the attitudes and approaches of graduate students differ significantly from introductory students and physics faculty on several measures.

\section{GROUPS THAT WERE ADMINISTERED THE AAPS SURVEY}

The final version of the AAPS survey was first administered anonymously to 16 physics graduate students enrolled in a graduate-level TA training course at the end of the onesemester course. The expert (favorable) responses are given in the Appendix along with the survey. Discussions with the graduate students after they took the survey showed that all of them interpreted that the survey was asking about problem solving in their own graduate courses and that they would have answered the questions differently if they were asked about their attitudes and approaches to solving introductory physics problems. Then, we administered the survey to 24 graduate students (there was overlap between the first cohort of 16 graduate students and this cohort) with the questions explicitly asking them to answer each question about their attitudes and approaches to introductory physics problem solving. Due to lack of class time, this second round of survey was administered online. We had individual discussions with four graduate students about the reasoning for their AAPS survey responses and invited all 24 graduate students who had answered the questions online to write a few sentences explaining their reasoning for selected survey questions online. We explicitly asked them to explain their reasoning when they answered the survey questions about problem solving in the graduate-level courses and separately for introductory physics. Ten graduate students (out of 24 who took the survey online) provided written reasonings for their responses. The following year, the survey was administered to 18 graduate students at the end of a graduate-level TA training course in which the graduate students were first asked to respond to the survey questions for problem solving in their own graduate courses and then for introductory physics problem solving (after they had submitted their survey responses to the graduate-level problem solving).

We also administered the AAPS survey to several hundred introductory students in two different first-semester and second-semester algebra-based physics courses and to students in the first and second-semester calculus-based courses. In particular, there were two sections of the first-semester algebra-based physics course with 209 students, two sections of the second-semester algebra-based physics course with 188 students, one first-semester calculus-based course section with 100 students and a second-semester calculus-based course section with 44 students. In all of these courses, students were given small amounts of bonus points for taking the survey. In addition, the survey was given to 31 students in an astronomy course which is the first astronomy course taken by students who plan to major in Physics and Astronomy (but less than 20\% of the students in this course actually end up majoring in Physics and Astronomy). None of the students in the astronomy course, who did not want to major in physics and astronomy, were required to take that course unlike the students in the introductory physics courses (the calculus-based introductory courses are dominated by engineering majors and algebra-based courses by those interested in health related professions who must take two physics courses to fulfill their requirements). For the astronomy course, the word "physics" in the survey everywhere was 
replaced by "astronomy," e.g., "in solving astronomy problems..." Also, the contexts (which were not related to astronomy) were removed from the last two questions (32) and (33) of the survey for astronomy students. Finally, the survey was given to 12 physics faculty who had taught introductory physics recently. Half of the faculty members were those who also gave the survey to their introductory students. The faculty member answered the survey questions for both introductory-level and graduate-level problem solving. We also discussed faculty responses to selected questions individually with some of them.

\section{VALIDITY AND RELIABILITY OF THE SURVEY}

We now address issues related to validity and reliability of the survey. Reliability refers to the relative degree of consistency between the survey scores, e.g., if an individual repeats the procedures [16]. One measure of reliability of a survey is the Cronbach's alpha $\left(\alpha_{c}\right)$ which establishes the survey's reliability via internal consistency check. The Cronbach's alpha $\left(\alpha_{c}\right)$ test was applied over all 33 questions for all groups $(\mathrm{N}=672)$ and the $\alpha_{c}=0.82$ which is reasonable from the standards of test-design [16]. As noted later, there is very little variability in the responses for some of the groups (e.g., faculty) so it does not make sense to calculate $\alpha_{c}$ separately for the various groups.

Validity refers to the appropriateness of interpreting the survey scores [16]. In order to develop the AAPS survey, we selected 16 questions from the APSS survey [10] and tweaked some of the questions for clarity based upon indepth interviews with five introductory physics students and three physics faculty members. These 16 questions constitute the first 14 questions and the last two questions of the AAPS survey, provided in the Appendix. We also developed 17 additional questions which were based upon discussions with the faculty members about productive approaches to problem solving, and modified them based upon the feedback from introductory students during interviews and discussions with some graduate students and three physics faculty members.

Content validity refers to the degree to which the survey items reflect the domain of interest (in our case, attitudes and approaches to problem solving) [16]. As noted earlier, we discussed with some faculty members their opinions about productive approaches to problem solving and took their opinions into account while developing the additional survey questions. We further addressed the issue of content validity by taking measures to ensure that the respondents interpret the survey questions as was intended. To this end we interviewed sample respondents from the introductory course, physics graduate students (mostly those enrolled in a TA training course) and faculty members. During the interviews and discussions, we paid attention to respondents interpretations of questions and modified the questions accordingly in order to make clear the actual intent of the questions. While the interviews with the introductory students were formal and tape-recorded, the discussions with the faculty members and graduate students were informal and were not taperecorded. The reason introductory physics students and faculty were sought for this purpose (in addition to the graduate students) is that we hypothesized that the responses of these two groups would be the most disparate and would provide the most diverse set of feedback for improving the preliminary survey. Some of the themes in the additional questions are related to the use of diagrams and scratch work in problem solving, use of "gut" feeling vs using physics principles to answer conceptual questions, reflection on one's solution after solving a problem to learn from it, giving up on a problem after $10 \mathrm{~min}$, preference for numerical vs symbolic problems and enjoying solving challenging physics problems. The in-depth interviews with five students from a firstsemester algebra-based class, and discussions with the graduate students and three physics faculty members helped modify the survey and were helpful in ensuring that the questions were interpreted clearly by both the experts and students at various anticipated levels of expertise.

Of approximately 40 introductory students responding to the invitation for paid interviews from an introductory physics course, five were selected. Since we wanted all students to be able to interpret the problems, two students were randomly chosen for interview from those who scored above $70 \%$ and three students were chosen who obtained below $70 \%$ on their first midterm exam. The survey questions were administered to all interviewed students in the form of statements that they could agree or disagree with on a scale of 1 (strongly agree) to 5 (strongly disagree) with 3 signifying a neutral response. During the individual interviews, students were also asked to solve some physics problems using a think-aloud protocol to gauge whether what they answered in the survey questions about their attitudes and approaches to problem solving were consistent with the attitudes and approaches actually displayed during problem solving. Within this protocol, we asked individuals to talk aloud while answering the questions. We did not disturb them while they were talking and only asked for clarifications of the points they did not make clear on their own later. While it is impossible to grasp all facets of problem solving fully by having students solve a few problems, a qualitative comparison of their answers to the survey questions and their actual approaches to solving problems was done after the interviews using the think aloud protocol. This comparison suggests that students were consistent in their survey responses in many cases but in some instances they selected more favorable (expertlike) responses to the survey questions than the expertise that was explicitly visible from their actual problem solving. In this sense, the favorable responses (at least for the introductory students) should be taken as the upper limit of the actual favorable attitudes and approaches to problem solving.

We also tested validity of the survey by comparing actual survey data with those predicted according to the assumption of expert-novice behaviors, pre-defining the majority faculty response for each question as the "expert" response [16]. In Table I, we display data for individual questions for each statistical group as well as the average response for all 33 questions for each of the groups in the "Avg." column. In the data reported in Table I, the average score is as defined by Cummings et al. [10] To calculate the average score for a question, $\mathrm{a}+1$ is assigned to each favorable response, $\mathrm{a}-1$ is assigned to each unfavorable response, and a 0 is assigned to 
TABLE I. Average scores for each group of students and faculty on each of the individual questions and averaged over all survey questions (see last entry). To calculate the average score for a question, $a+1$ is assigned to each favorable response, $\mathrm{a}-1$ is assigned to each unfavorable response, and a 0 is assigned to neutral responses. One then averages these values for everybody in a particular group (e.g., faculty-Intro) to obtain an average score for that group. "Intro" and "Self" with Graduate students implies problem solving in "introductory physics" and "graduate-level physics courses" respectively.

\begin{tabular}{|c|c|c|c|c|c|c|c|}
\hline Problem number & 1 & 2 & 3 & 4 & 5 & 6 & 7 \\
\hline Faculty-intro & 0.83 & 1.00 & 0.50 & 0.92 & 0.92 & 1.00 & 0.83 \\
\hline Faculty-grad & 1.00 & 0.92 & 0.36 & 1.00 & 1.00 & 1.00 & 1.00 \\
\hline Graduate students-intro & 0.71 & 0.42 & -0.04 & 0.83 & 0.17 & 0.75 & 0.83 \\
\hline Graduate students-self & 0.40 & 0.63 & -0.13 & 0.75 & 0.63 & 0.25 & 0.88 \\
\hline Astronomy students & 0.45 & 0.48 & -0.16 & 0.58 & 0.13 & 0.71 & 0.84 \\
\hline All introductory students & 0.14 & 0.19 & 0.15 & 0.41 & 0.16 & 0.24 & 0.61 \\
\hline Problem number & 8 & 9 & 10 & 11 & 12 & 13 & 14 \\
\hline Faculty-intro & 0.92 & 0.58 & 0.92 & 0.67 & 0.83 & 1.00 & 0.50 \\
\hline Faculty-grad & 1.00 & 0.92 & 1.00 & 0.75 & 1.00 & 0.92 & 0.92 \\
\hline Graduate students-intro & 0.83 & 0.46 & 0.88 & 0.67 & 0.54 & 0.88 & 0.88 \\
\hline Graduate students-self & 1.00 & 0.31 & 0.69 & 0.33 & 0.44 & 0.94 & 0.81 \\
\hline Astronomy students & 0.77 & 0.35 & 0.94 & 0.23 & 0.10 & 0.74 & 0.77 \\
\hline All introductory students & 0.67 & 0.24 & 0.58 & -0.03 & -0.06 & 0.56 & 0.32 \\
\hline Problem number & 15 & 16 & 17 & 18 & 19 & 20 & 21 \\
\hline Faculty-intro & 1.00 & 0.67 & 1.00 & 0.92 & 1.00 & 0.75 & 1.00 \\
\hline Faculty-grad & 0.92 & 0.75 & 0.92 & 0.92 & 1.00 & 0.75 & 1.00 \\
\hline Graduate students-intro & 0.96 & 0.50 & 0.79 & 0.96 & 0.88 & 0.38 & 0.92 \\
\hline Graduate students-self & 0.94 & 0.31 & 0.50 & 0.88 & 0.56 & 0.25 & 0.94 \\
\hline Astronomy students & 0.29 & 0.52 & 0.06 & 0.19 & 0.84 & 0.32 & 0.90 \\
\hline All introductory students & 0.74 & 0.23 & 0.55 & 0.69 & 0.77 & -0.19 & 0.71 \\
\hline Problem number & 22 & 23 & 24 & 25 & 26 & 27 & 28 \\
\hline Faculty-intro & 1.00 & 0.92 & 0.42 & 0.92 & 1.00 & 0.92 & 1.00 \\
\hline Faculty-grad & 1.00 & 1.00 & 0.67 & 1.00 & 0.92 & 1.00 & 1.00 \\
\hline Graduate students-intro & 1.00 & 1.00 & 0.21 & 0.54 & 0.71 & 0.67 & 0.96 \\
\hline Graduate students-self & 1.00 & 0.75 & 0.19 & 0.38 & 0.50 & 0.63 & 0.88 \\
\hline Astronomy students & 0.77 & 0.74 & 0.06 & 0.68 & 0.55 & 0.74 & 0.87 \\
\hline All introductory students & 0.52 & 0.40 & 0.43 & 0.56 & 0.37 & 0.03 & 0.75 \\
\hline Problem number & 29 & 30 & 31 & 32 & 33 & Avg. & \\
\hline Faculty-intro & 1.00 & 0.93 & 1.00 & 1.00 & 1.00 & 0.88 & \\
\hline Faculty-grad & 1.00 & 1.00 & 1.00 & 1.00 & 1.00 & 0.92 & \\
\hline Graduate students-intro & 1.00 & 0.92 & 0.92 & 1.00 & 0.83 & 0.73 & \\
\hline Graduate students-self & 1.00 & 0.69 & 1.00 & 0.88 & 0.19 & 0.62 & \\
\hline Astronomy students & 0.68 & -0.19 & -0.13 & 0.68 & 0.50 & 0.49 & \\
\hline All introductory students & 0.74 & -0.04 & 0.08 & 0.70 & 0.46 & 0.33 & \\
\hline
\end{tabular}

neutral responses. We then average these values for everybody in a particular group (e.g., faculty) to obtain an average score for that group. Thus, the average score on each question for a group indicates how expertlike the survey response of the group is on each survey question. Table I shows that the faculty had unanimous or close to unanimous agreement on most of the survey questions. These results support con- tent validity of the survey. Table I also shows that faculty members answered the questions in a more expertlike fashion than graduate students, who in turn were more expertlike than introductory-level students. The difference between faculty and graduate students holds both for problem solving in graduate-level problems as well as problem solving in introductory-level problems. Similarly, the graduate stu- 
TABLE II. Effect sizes between two groups. The number of people in each group is given in the parenthesis. All effect sizes are positive because they are always taken such that $\mu_{2}<\mu_{1}$ in the calculations (i.e., subtracting the higher mean from the lower mean; see Table I). ANOVA using Pairwise $t$-test shows that the differences between all the groups is significant except that between faculty members for introductorylevel and graduate-level problem solving ( $p=0.269$ for that case). Therefore, Cohen's $d$ was not calculated for Faculty-intro vs. faculty-grad.

\begin{tabular}{lcccccc}
\hline \hline Cohen's d & Intro physics & Astronomy & Grad-intro & Grad-self & Faculty-intro & Faculty-grad \\
\hline Intro physics (541) & 0.62 & 1.60 & 1.30 & 2.18 & 2.36 \\
Astronomy (31) & & 1.42 & 0.90 & 2.19 & 2.43 \\
Grad-intro (42) & & & 0.46 & 1.19 & 1.53 \\
Grad-self (34) & & & 1.43 & 1.71 \\
Faculty-intro (12) & & & & \\
Faculty-grad (12) & & & & \\
\hline \hline
\end{tabular}

dents' responses are more expertlike for introductory-level problems than introductory students' responses are about problem solving at the introductory-level. While these differences cannot be quantified a priori, such differences can be expected based upon the known expertise of each of these groups in physics. All these differences are statistically significant $(p<0.05)$. These consistencies further provide validity to the survey.

To determine whether the differences between the groups are statistically significant and there is an appreciable effect size, we examined the groups as follows: all introductory physics students (we combined these classes since we did not find statistical differences between different introductory physics classes); the astronomy group; all graduate students for introductory problems; all graduate students for graduatelevel problems; all faculty for introductory problems; and all faculty for graduate-level problems. The effect sizes between groups over all 33 questions were calculated in the form of Cohen's d $\left[=\left(\mu_{1}-\mu_{2}\right) / \sigma_{\text {pooled }}\right]$, calculating individual group means (on a scale of -1 to +1 ) and standard deviations.[17] Table II shows that the effect sizes between groups of different levels of expertise have a large to very large effect size $(1<d<2.5)$, in favor of the more assumed expertlike group [16]. Individual $p$-values for pairwise $t$-tests [16] between each group shows that all differences are statistically significant except for the difference between the two faculty groups. Again these effect sizes are qualitatively consistent with the expected trends based upon the expertise of each group and provides validity to the survey.

\section{RESULTS}

As noted earlier, the survey questions are designed in a "agree" or "disagree" format (see the Appendix). There is leeway to agree or disagree "somewhat" or "strongly" (although we did not distinguish between these in our analysis presented here), and one may also select a neutral response. The favorable (expert) responses for each question based upon the responses chosen by most physics faculty are also given in the Appendix. As noted earlier, Table I shows the net average responses for all groups for each individual question and averaged over all questions (see the last entry in
Table I). In Table I, the introductory physics students from both semesters of algebra-based and calculus-based courses were lumped into one group because there was no significant difference between the "net" average survey responses of these groups.

In Table I, we followed the method for reporting data used by Cummings et al. [10]. A second method for representing data separately shows the average percentage of favorable and unfavorable responses for each question for each group (the neutral responses are $100 \%$ minus the percentage of favorable and unfavorable responses). We will use this second method of data representation for all of our graphical representations of data below using histograms. Moreover, since there are no significant differences between faculty responses for problem solving at the introductory and graduate levels except for a couple of questions (see Table I), the histograms will only display one of the two sets (faculty responses for introductory-level problem solving).

We now examine graduate students' survey responses to individual questions (recall that the effect size between them and faculty in Table II appears to be similar to the effect size between them and introductory students). Comparison of the graduate students' problem solving attitudes and approaches for introductory and graduate-level problems in Table II shows that there is small to moderate effect size $(0.4<d$ $<0.6$ ). However, if problem solving attitudes and approaches of a given group (e.g., graduate students) did not depend at all on how difficult the problem was (e.g., whether it was introductory or graduate-level problem), there would be a very small effect size $(d<0.2)$. This moderate effect size suggests a difference in attitudes and approaches for a group with different levels of problems (introductory vs graduate level), and is discussed in the following sections.

\section{A. Comparison of graduate students' survey responses for graduate level vs introductory-level problem solving}

Figure 1 compares the AAPS survey responses of graduate students to selected questions for which differences were observed when they answered the questions about problem solving in their graduate courses and problem solving in introductory physics. The error bars on the histograms (and in 


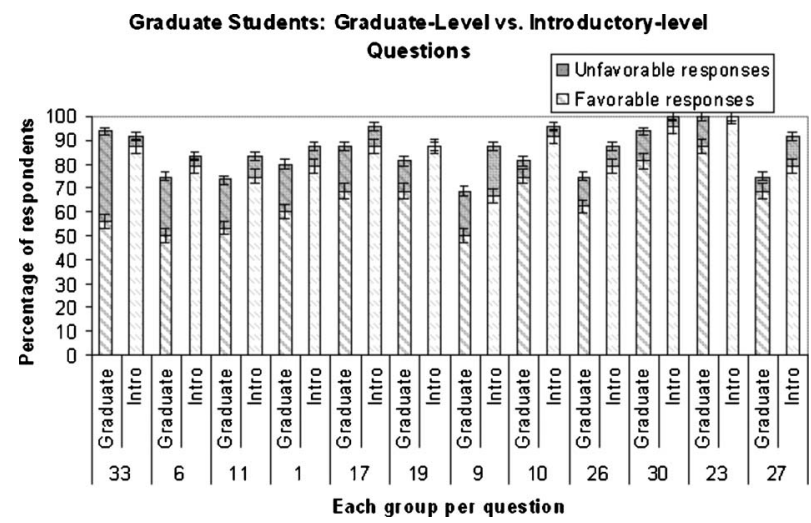

FIG. 1. Comparison of graduate students' survey responses to 12 selected questions when considering introductory-level problem solving and graduate-level problem solving. The order of the questions in the histogram is such that the difference between the introductory-level problem solving ("Intro" in the figure) and graduate-level problem solving ("Graduate" in the figure) is largest for the first question [question (33)] and second largest for the second question [question (6)] etc. Error bars shown here (and in all other figures) are the standard errors. The responses to these questions are more favorable for introductory-level problem solving than for graduate-level problem solving. The neutral percent responses can be found by subtracting from 100, the percentage of favorable and unfavorable responses.

all the other figures in this paper) show the standard error. One typical difference between introductory and graduatelevel problem solving is that the graduate students display more expertlike (favorable) attitudes and approaches while solving introductory-level problems than while solving graduate-level problems. For example, in response to question (1) for problem solving in their graduate-level courses, approximately $40 \%$ of the graduate students felt that if they were not sure about the right way to start a problem, they would be stuck unless they got help but only $20 \%$ felt this way when solving introductory physics problems. Also, they were more likely to reflect upon physics principles that may apply and see if they yield a reasonable solution when not sure about the approach while solving introductory problems than while solving graduate-level problems [see response to question (10) in Fig. 1]. They were also more likely to be able to tell that their answer was wrong without external input while solving introductory problems than graduatelevel problems [see response to question (6) in Fig. 1]. Graduate students were approximately $20 \%$ more likely to claim that they routinely use equations to calculate answers even if they are nonintuitive while solving graduate-level problems than while solving introductory-level problems [see response to question (11) in Fig. 1].

While none of the graduate students claimed they would give up solving an introductory physics problem if they could not solve it within $10 \mathrm{~min}$, approximately $15 \%$ claimed they would give up after $10 \mathrm{~min}$ while solving a graduatelevel problem [see response to question (23) in Fig. 1]. Moreover, while approximately $80 \%$ of the graduate students claimed they enjoy solving introductory physics problems even though it can be challenging at times, less than $70 \%$ of them said the same about the graduate-level problems [see response to question (27) in Fig. 1]. Also, more graduate students claimed that it is useful for them to solve a few difficult problems using a systematic approach and learn from them rather than solving many similar easy problems one after another when solving introductory-level problems than for graduate-level problems [see response to question (26) in Fig. 1].

As shown in Table I, the introductory physics students noted that they enjoyed solving challenging problems even less than the graduate students and were also less likely to find solving a few difficult problems more useful than solving many easy problems based upon the same principle [see introductory students' responses to question (26) and (27) in Table I]. One introductory student stated in an interview that he feels frustrated with his incorrect problem solution and feels satisfied when he gets a problem right, which motivates him to continue to do problem solving. Therefore, he likes easier problems.

In response to survey question (33), close to $90 \%$ of the graduate students agreed that two introductory-level problems, both of which involve conservation of energy, can be solved using similar methods whereas only approximately $55 \%$ of them agreed that both problems can be solved using similar methods when solving graduate-level conservation of energy problems (see Fig. 1). Individual discussions with a subset of graduate students suggest that they felt that since air-resistance and friction were involved, they may have to use different methods to solve the problems. In particular, they noted that they often use different methods involving Lagrangians and Hamiltonians to solve complicated problems in graduate-level courses and they were not sure if the same technique will be useful in problems involving friction and air-resistance. In response to survey question (33), all of the physics faculty noted that both problems can be solved using similar methods (see Table I). The responses of many graduate students to question (33) points to the fact that graduate students who are taking graduate-level physics courses are immersed in learning complicated mathematical techniques and they are evaluating their survey responses in light of their experiences with mathematical tools. When a physics faculty member, who had taught several "core" graduate courses routinely, was shown the responses of graduate students to question (33), he commented that he has observed that, sometimes the graduate students are so focused on mathematical manipulations in the graduate-level courses, they tend to use unnecessarily complicated techniques even when they are asked questions which can be solved using introductory-level techniques, e.g., for problems related to Gauss's law or Ampere's law.

\section{B. Comparison of graduate students' survey responses with those of other groups}

Next, we compare graduate students' responses on selected questions on the AAPS survey with those of the physics faculty and introductory physics and astronomy students.

\section{Graduate Students are still developing expertise in graduate-level problem solving}

In the previous section, we discussed that the average responses of graduate students to graduate-level problem 


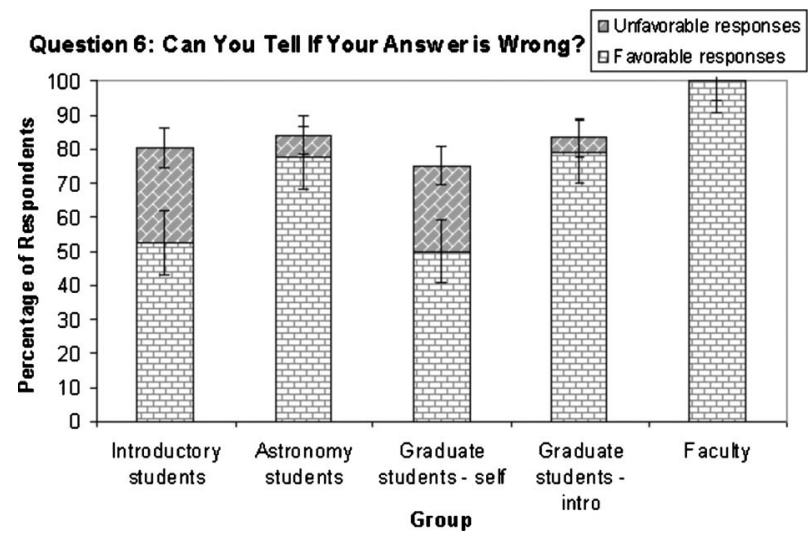

FIG. 2. Histogram showing favorable (agree) and unfavorable (disagree) responses for survey question (6). The histogram shows that faculty were always aware of when they were wrong in problem solving but other respondents were less certain. Only about $50 \%$ of graduate students could tell that their answers were wrong in graduate-level problem solving. Graduate students-self and Graduate Students-intro refer to Graduate students' response for graduate-level problem solving and introductory-level problem solving, respectively.

solving was less expertlike than their responses to introductory-level problem solving. Comparison of average graduate students' responses for graduate-level problem solving with those of physics faculty also suggests that graduate students are still developing expertise in problem solving at the graduate level. For example, Fig. 2 shows that, in response to question (6), all of the physics faculty noted that while solving physics problems they could often tell when their work and/or answer is wrong even without external resources but only approximately 50\% of the graduate students could do so while solving graduate-level problems and approximately $80 \%$ of the graduate students could do so for introductory-level problem solving. Moreover, the survey response of the graduate students to this question for graduatelevel problems is similar to that of the introductory physics students for introductory-level problems. Such similarity suggests that while graduate students may be experts in solving introductory problems, they are still developing expertise in solving graduate-level problems.

Figure 3 shows that, in response to question (11) about whether equations need not be intuitive in order to be used and whether they routinely use equations even if they are nonintuitive, graduate students' responses while solving introductory physics problems were similar to those of faculty and approximately $75 \%$ disagreed with the statements (favorable response). However, when answering graduate-level problems, only slightly more than $50 \%$ of the graduate students noted that equations must be understood in an intuitive sense before being used. Individual discussions suggest that the graduate students felt that sometimes the equations encountered in the graduate courses are too abstract and they do not have sufficient time to make sense of them and ensure that they have built an intuition about them. The following sample responses from some graduate students reflect their sentiments:

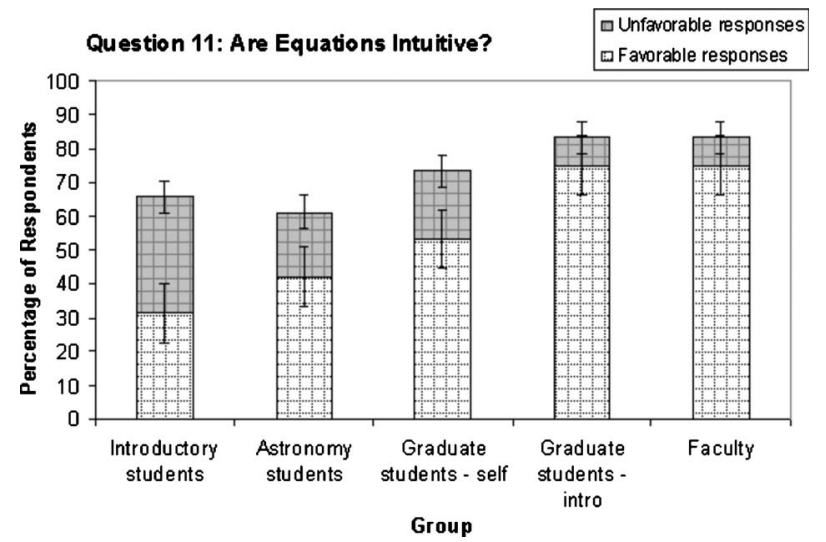

FIG. 3. Histogram showing favorable (disagree) and unfavorable (agree) responses for survey question (11). The histogram shows that many more graduate students disagreed that they routinely use equations to calculate answers even if they are nonintuitive for introductory-level problem solving than graduate-level problem solving. Almost equal percentage of introductory physics students agreed and disagreed with the statement.

(i) “...you just cannot understand everything. So it's ok to deal with the homework first. But I really feel bad when I do plug and chuck [sic]."

(ii) "I am often still presented with equations to calculate something without enough motivation to understand the process, even at the graduate level, and being able to use the equation and accept that you'll understand it later is often necessary. For students' first course in physics, this is more the rule than the exception at some level..."

(iii) "I remember physics via the equations, so I try my best to always understand the meaning. But if I can't, I fall back on "this is the equation, use it"."

(iv) "As an introductory student I had the point of view that the equations are right so my intuition must be wrong. I used equations to get the answer whether it made sense at first or not, but I trained my intuition with every such result. I had more faith in the physics that is taught to me than the physics intuition I acquired just by observation. As a graduate student, one is already used to the unintuitive results being the correct one, they have by then become intuitive."

The last graduate student quoted above expresses an interesting view that by the time one becomes a graduate student in physics, one may have learned to accept nonintuitive results and such results start appearing intuitive. The responses of the introductory physics students suggest that they are even more likely than graduate students to use equations to calculate answers even if they are nonintuitive (see Fig. 3). This finding is consistent with the prior results that suggest that many introductory students view problem solving in physics as an exercise in finding the relevant equations rather than focusing on why a particular physics principle may be applicable and building an intuition about a certain type of physics problems [4,5].

In response to question (25) about whether individuals make sure they learn from their mistakes and do not make 


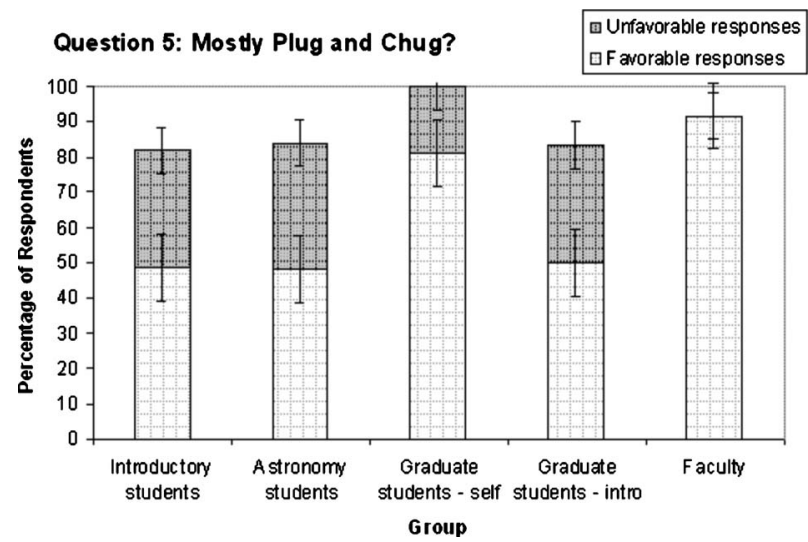

FIG. 4. Histogram showing favorable (disagree) and unfavorable (agree) responses for survey question (5) about whether problem solving in physics is mainly an exercise in finding the right formula. The histogram shows that a large percentage of nonfaculty respondents from all groups agreed with the statement or were neutral.

the same mistakes again, all but one physics faculty agreed with the statement (favorable) and one was neutral. On the other hand, only slightly more than $60 \%$ and $70 \%$ of the graduate students agreed with the statement when pertaining to solving graduate-level problems and introductory-level problems, respectively. Graduate students's net favorable scores for question (25) in Table I suggests that many graduate students had unfavorable response to this question especially for graduate-level problem solving.

The response of introductory physics students to question (25) was comparable to that of graduate students for introductory physics problem solving but it is less expertlike than the physics faculty. One introductory student said he did not review errors on the midterm exam as much as he would on homework, partly because the homework problems may show up on a future test but partly because he didn't like staring at his bad exam grade. The reluctance to reflect upon tests is consistent with our earlier findings for an upper-level undergraduate quantum mechanics course which demonstrated that many students did not reflect automatically on their mistakes in the midterm exams for similar reasons [18].

\section{Unexpected Trends require careful analysis}

The average responses to some survey questions for various groups are counterintuitive and require careful analysis. Figure 4 shows that on question (5) of the survey, while no faculty agreed with the statement (no unfavorable response) that problem solving in physics basically means matching problems with the correct equations and then substituting values to get a number, more than $30 \%$ of the graduate students agreed with the statement (unfavorable) in the context of introductory-level problem solving and approximately $20 \%$ agreed with the statement for graduate-level problem solving. However, Fig. 4 also shows the counterintuitive trend that the average responses of introductory physics students to question (5) were indistinguishable from those of the graduate students for introductory physics problem solving. Individual discussions and written explanations suggest that

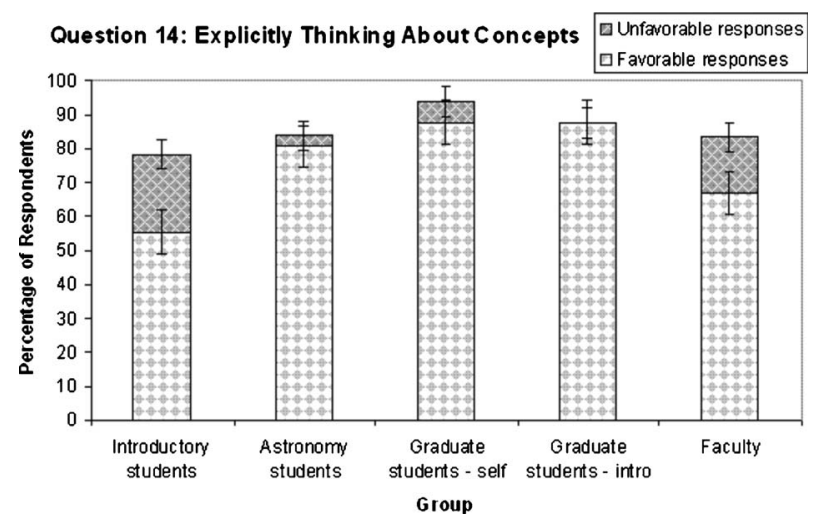

FIG. 5. Histogram showing favorable (agree) and unfavorable (disagree) responses for survey question (14). While the trend in the figure from introductory students to faculty may appear to be inconsistent with expectations, some faculty in individual discussions noted that they do not explicitly think about concepts that underlie the problem "while" solving problems because the concepts have become obvious to them. The introductory students often do not think about concepts because they believe in a plug and chug approach to problem solving in physics.

the reasoning of many graduate students differs from the reasoning of a typical introductory physics student although the average responses of these groups are superficially the same. In particular, for introductory-level problem solving, many graduate students felt so comfortable with the applications of basic principles that not much explicit thought was involved in solving introductory-level problems. For example, in response to question (5), one graduate student noted

(i) "Well for introductory physics this is true. But, in more advanced problems you kind of have to setup the equations."

On the other hand, prior research suggests that many introductory physics students think that physics is a collection of disconnected facts and formulas and use a "plug and chug" approach to problem solving without thinking if a principle is applicable in a particular context $[4,5]$.

Some graduate students reflected explicitly on their introductory physics experiences and compared it to the graduatelevel experiences in problem solving. The following is a reflective response of one graduate student

(ii) "you can get an expression from two others without understanding how or why. As an introductory student I probably did this more because the expressions were simpler and easier to manipulate without a $100 \%$ understanding. My motives were also more to get the work done than to learn every detail."

Figure 5 shows that, in response to question (14) regarding whether they always explicitly think about concepts that underlie the problems when solving physics problems, close to $90 \%$ of the graduate students agreed (favorable) that they do so both in the context of introductory and graduate-level problem solving. However, only approximately $65 \%$ and $55 \%$ of the physics faculty and introductory physics students 
agreed, respectively. The trend in Fig. 5 going from the introductory students to faculty is not consistent with expectations at first, but individual discussions suggest that some faculty do not always explicitly think about the concepts that underlie the problem because the concepts have become obvious to them due to their vast experience. They are able to invoke the relevant physics principles, e.g., conservation of mechanical energy or conservation of momentum, automatically when solving an introductory problem without making a conscious effort. In fact, question (14) is one of those rare questions on the survey for which the faculty responses were different for introductory and graduate-level problem solving (in particular, more than $90 \%$ noted that they explicitly think about concepts that underlie the problems for graduate-level problems). In contrast, prior research suggests that introductory physics students often do not explicitly think about the relevant concepts because they often consider physics as consisting of disconnected facts and formulas and associate physics problem solving as a task requiring hunting for the relevant formulas without performing a conceptual analysis and planning of the problem solution $[4,5]$. Thus, the reasoning behind the less favorable responses of faculty to question (14) is generally very different from the reasonings behind the introductory physics students' responses.

\section{Introductory physics students are not on par with physics graduate students and faculty}

Survey responses to some questions suggest that the introductory physics students' attitudes and approaches to solving introductory physics problems are not as expertlike as physics graduate students and faculty. For example, survey responses suggest that manipulation of symbols rather than numbers increases the difficulty of a problem for many introductory physics students. Question (30) asked whether symbolic problems were more difficult than identical problems with numerical answers and question (31) asked if individuals preferred to solve a problem with a numerical answer symbolically first and only plug in the numbers at the very end. Figures 6 and 7 show that the responses of graduate students for both introductory and graduate-level problem solving are comparable to physics faculty but introductory students' responses are very different. In response to question (30), only approximately $35 \%$ of the introductory physics students disagreed with the statement (favorable response) that it is more difficult to solve a problem symbolically, and in response to question (31), only $45 \%$ agreed with the statement (favorable response) that they prefer to solve the problem symbolically first and only plug in the numbers at the very end.

Individual discussions with some introductory physics students suggest that they have difficulty keeping track of the variables they are solving for if they have several symbols floating around, which motivates them to substitute numbers at the beginning of the solutions [19]. Some introductory students noted that they did not like carrying expressions involving symbols from one equation to another because they were afraid that they will make mistakes in simplifying the expressions.

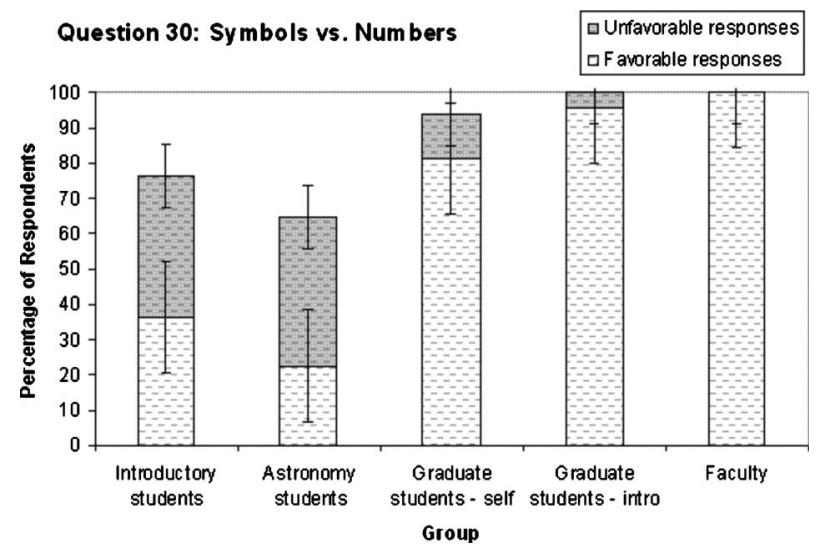

FIG. 6. Histogram showing favorable (disagree) and unfavorable (agree) responses for survey question (30). The histogram shows that faculty and graduate students did not believe that it is more difficult to solve a physics problem with symbols than solving an identical problem with numerical answer but introductory physics and astronomy students often did.

\section{Graduate student attitudes and approaches about introductory physics problem solving is not always as expertlike as physics faculty}

The responses to some survey questions suggest that the attitudes and approaches of graduate students regarding solving introductory-level problems is not as expertlike as physics faculty. For example, Fig. 8 shows that, in response to question (2) about whether they often make approximations about the physical world when solving physics problems, all faculty noted that they do so. However, only approximately $75 \%$ and $65 \%$ of graduate students noted they do so for graduate-level problem solving and introductory-level problem solving, respectively. Individual discussions and written explanations suggest that the graduate students have different views about making approximations about the physical world as illustrated by the sample comments below:

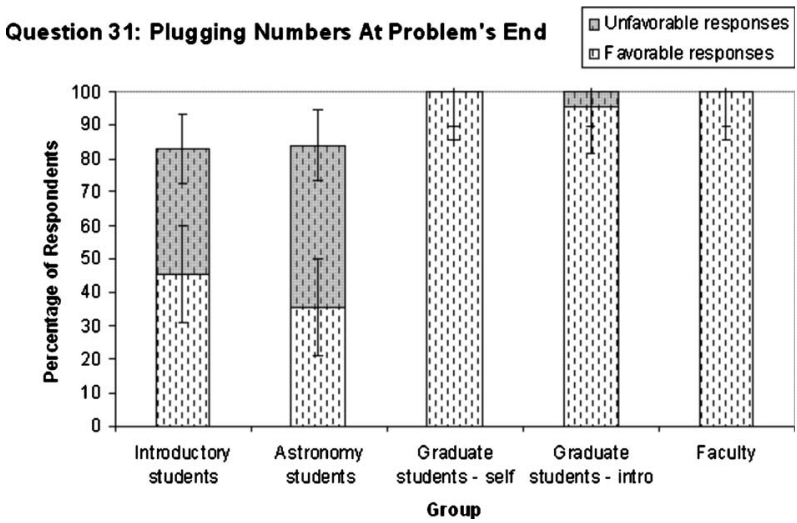

FIG. 7. Histogram showing favorable (agree) and unfavorable (disagree) responses for survey question (31). The histogram shows that faculty and graduate students preferred to solve a problem symbolically first and only plug in the numbers at the very end but less than half of the introductory physics and astronomy students agreed with them. 


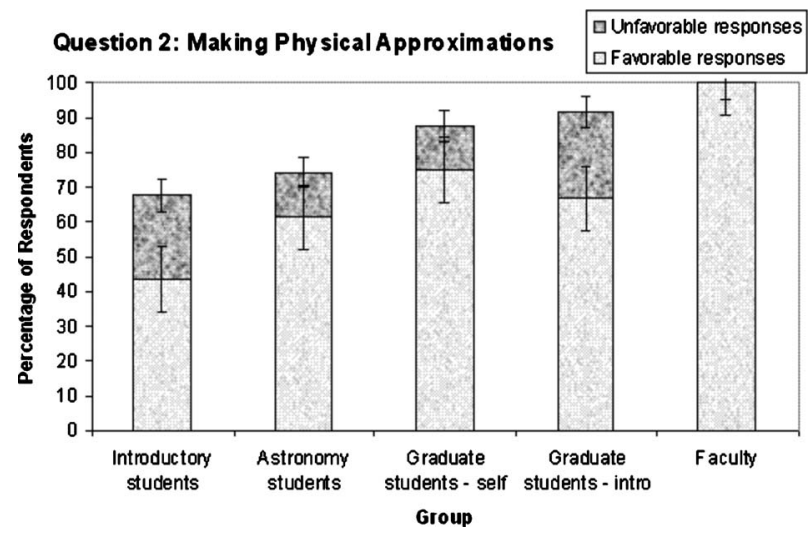

FIG. 8. Histogram showing favorable (agree) and unfavorable (disagree) responses for survey question (2). The histogram shows that all faculty agreed that they often make approximations about the physical world but other respondents, including physics graduate students, were not always in agreement.

(i) "I don't connect the physics problems to real world very much."

(ii) "it's stat mech, in which I do whatever I have to [including approximations], to make the answer come out (and usually that is correct)."

(iii) "Solving physics problems as an introductory physics student I was perhaps more prone to this, thinking about how a block would slide down an incline. As I became more familiar with the extent of "nonphysical" approximations we made such as a frictionless world, I learned to separate problem solving space and real life space. I find that this is one aspect of physics problem solving that is harder for introductory-level courses than graduate courses, the problems we solve [in introductory physics] are farther away from the physical world than graduate-level problems. It keeps the math manageable and the physics concepts manageable but it makes them less intuitive."

(iv) "Many introductory-level problems are well defined and ideal, which doesn't require approx."

In contrast to the last graduate student's comment, individual discussions with some faculty suggest that they considered idealization of the problem in introductory and graduate-level physics, e.g., framing problems without friction or air resistance, considering spherical cows or point masses, the infinite square well or hydrogen atom with only the Coulomb force, etc. as making approximations about the physical world and they felt that such approximations were helpful for getting an analytical answer and for building intuition about physical phenomena. It is possible that approximately $25 \%$ of the graduate students who noted that they don't make approximations while solving introductory physics problems have not carefully thought about the role of approximations about the physical world in introductory physics problem solving.

Figure 9 shows that, in response to question (12) regarding whether physics involves many equations each of which applies primarily to a specific situation, all but one physics

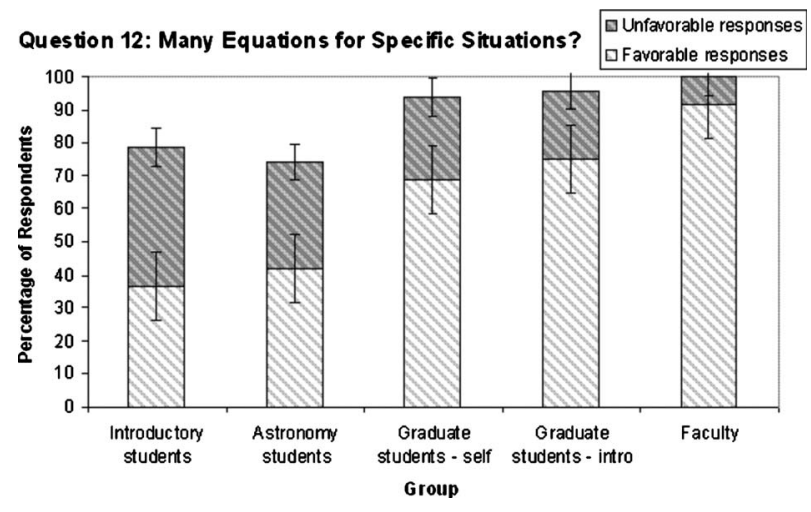

FIG. 9. Histogram showing favorable (disagree) and unfavorable (agree) responses for survey question (12) about whether physics involves many equations each of which applies primarily to a specific situation. As we go from the introductory physics and astronomy students to faculty, the disagreement with the statement (favorable response) increases.

faculty members disagreed with the statement (favorable) but less than $70 \%$ of the graduate students disagreed with it when solving graduate-level problems. The percentage of introductory physics students who disagreed with the statement was slightly more than $35 \%$ and slightly more than $40 \%$ for the astronomy students. These responses are commensurate with the expertise of each group and points to the fact that experts are more likely to discern the coherence of the knowledge in physics and appreciate how very few laws of physics are applicable in diverse situations and can explain different physical phenomena.

\section{Some questions do not have a clear-cut expertlike response}

If faculty is taken as experts, their responses to the survey questions indicate that there are some questions whose answers may not necessarily represent clear-cut favorable or unfavorable traits without disagreement from several faculty. For example, for question (24), there are differences in faculty responses for introductory-level vs graduate-level problem solving. For example, less than $70 \%$ of the faculty (and an even smaller percentage of graduate students) noted that they liked to think through a difficult physics problem with a peer when solving introductory physics problem but $83 \%$ of the faculty liked to work with a peer for difficult graduatelevel problems. Individual discussions with some of the faculty members suggests that whether one continues to persevere individually or works with a peer to solve a challenging introductory or graduate-level problem depends on an individual's personality. The graduate student reasonings for wanting to work with a peer or not were varied as illustrated by the following examples:

(i) "This is not true (usefulness of talking to peers) for introductory-level problems because, typically these types of problems are quite direct. Thinking about them for a little while always produces some result. For graduate-level problems, it is almost essential to work with others because of the complex line of thought it takes to solve some problems." 


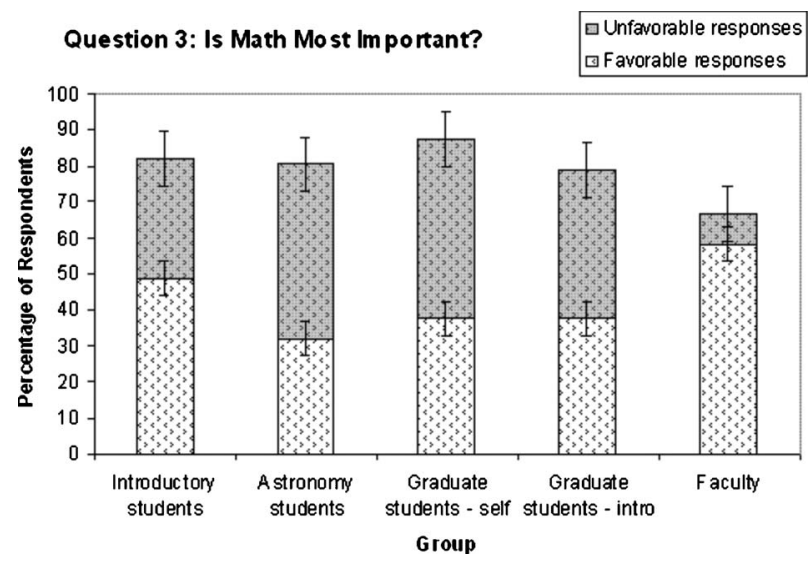

FIG. 10. Histogram showing favorable (disagree) and unfavorable (agree) responses for survey question (3) about whether mathematics is the most important part of the problem solving process. The histogram shows that a large percentage of nonfaculty respondents from all groups agreed with the statement (unfavorable).

(ii) "Bouncing ideas with someone gives me sort of a chance to see the problem from the outside. You somehow see another point of attack. If you are stuck on a problem, usually the reason is that the approach is a dead end or too complex. Having someone to talk to forces you to think with a different perspective."

(iii) "I would like to think out by myself."

(iv) "As an introductory student it (working with peers) can make things more complicated, I would rather ask the TA. Other students have the same misconceptions as I do so they aren't a good source. As a graduate student, I saw that everyone was benefiting from collaboration. I know I would too. I just don't like to do anything with a peer but that's purely a social issue, I believe it is useful to work with peers."

Thus, while many graduate students agree that talking to peers is helpful (at least for challenging problems) some of them are inherently more averse to discussions with peers than others.

Figure 10 shows that in response to question (3), regarding whether being able to handle the mathematics is the most important part of the process in solving a physics problem, less than $60 \%$ of the physics faculty disagreed with the statement (favorable response) and approximately $35 \%$ were neutral. Among graduate students, less than $40 \%$ of the students disagreed with the statement (favorable response) both for problem solving at the introductory and graduate levels. Roughly 50\% of the graduate students agreed (unfavorable response) that mathematics is the most important part of the process in problem solving at the graduate level and more than 40\% agreed (unfavorable response) with it for introductory-level problem solving. Individual discussions with the graduate students suggest that, in response to question (3), some students felt that facility with high level mathematics is the most important skill for excelling in their graduate courses. Some graduate students felt that basic mathematics is very important for doing well in introductory problem solving as well, whereas others did not think mathematics was as important, especially for the algebra-based courses. The following are examples of responses from the graduate students that convey the sentiments:

(v) "if I was teaching a class of med. students, the concepts are certainly most important... However, a class of engineers really need to know how to get the right answer so the things that they build, function as they are supposed to. I would say in this case that math and concepts are equally important. For graduate-level problems, I believe mathematics becomes more essential over introductory-level problems."

(vi) "From my point of view, the introductory physics concepts are very easy to understand. It's in the details of problem solving that you could get stuck like encountering a difficult integration for example or some tricky algebra."

(vii) "In introductory physics, this was not at all the case, the math was easy enough, I needed little more than high school calculus, so it was getting the physics down and understanding the language of physics, the new jargon, new concepts etc. Once the concepts became familiar enough and I moved on to graduate school, math became my biggest problem. From vector calculus to advanced linear algebra to special functions to group theory, the math is often harder. I find it a lot easier to think about physics and the universe conceptually (now that I am armed with such intuition and interest) but trying to actually 'solve' a physics problem comes down to the math, which I find hard."

Individual discussions with some physics faculty about question (3) suggests that they believed that conceptual knowledge in physics was the central aspect of physics problem solving in both introductory and graduate-level problem solving. But some faculty who were neutral in response to question (3) emphasized that the students may not excel in physics without a good grasp of mathematics even though concepts are central to learning physics. The views of more graduate students (compared to faculty) about mathematics being the most important aspect of physics problem solving may stem from the fact that graduate students have recently taken graduate- and undergraduate-level courses in which their grades often depend not as much on their conceptual knowledge but on their mathematical facility. However, question (3) is one of the survey questions for which there isn't a strong agreement on favorable response among the faculty either (see Fig. 10).

Similarly, in response to question (16), only $75 \%$ of faculty for introductory level and a somewhat higher percentage for graduate level (and a much smaller percentage of graduate students in each case) noted that, while answering conceptual physics questions, they use the physics principles they usually think about when solving quantitative problems rather than mostly using their "gut" feeling. Discussions elucidated that the faculty members' use of their "gut" feeling to answer conceptual questions (rather than explicitly invoking physics principles) was often due to the fact that they had developed good intuition about the problems based upon their vast experience. Thus, they did not need to explicitly think about the physical principles involved.

Incidentally, in response to question (16), 50\% of the introductory physics students claimed that they use their "gut" 


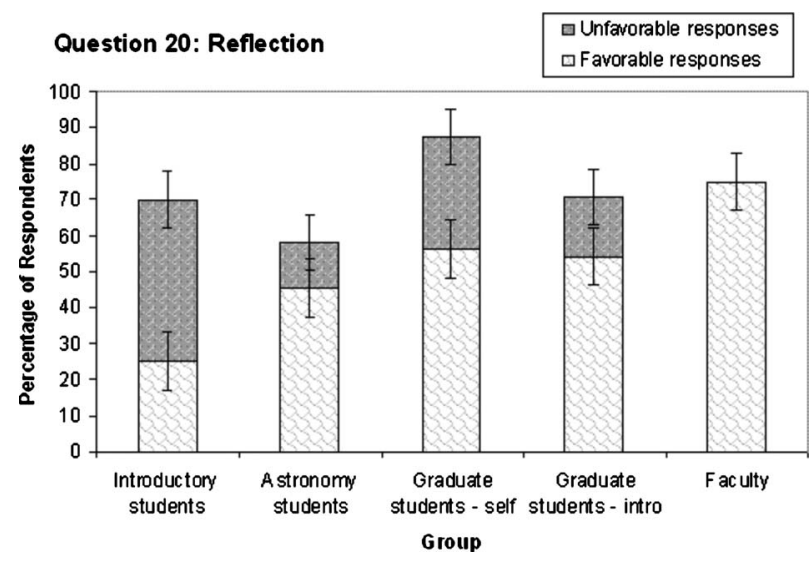

FIG. 11. Histogram showing favorable (agree) and unfavorable (disagree) responses for survey question (20). The histogram shows that none of the groups had $80 \%$ individuals who agreed that they take the time to reflect and learn from the problem solutions after solving problems but the reasons for the lack of reflection varied across different groups.

feeling to answer conceptual questions rather than invoking physics principles. Our earlier research and those of others suggest that introductory students often view conceptual questions as guessing tasks and use their "gut" feeling rather than explicitly considering how the physical principles apply in those situations $[4,20,21]$. One interviewed introductory student stated that he would not consider principles when answering a conceptual question because overanalyzing the problem is more likely to make his answer wrong. When Mazur from Harvard University gave the Force Concept Inventory Conceptual standardized test [22] to his introductory students, a student asked if he should do it the way he really thinks about it or the way he has been taught to think about it in the class [20]. It appears that students sometimes hold two views simultaneously, where one is based upon their gut feeling and another is based upon what they learned in the physics class, and these views coexist and are difficult to merge.

\section{Why don't faculty and graduate students reflect after solving a problem?}

Problem solving is often a missed learning opportunity because, in order to learn from problem solving, one must reflect upon the problem solution [18,23-27]. For example, one must ask questions such as "what did I learn from solving this problem?," "why did the use of one principle work and not the other one?" or "how will I know that the same principle should be applicable when I see another problem with a different physical situation?." Unfortunately, the survey results suggest a general lack of reflection by individuals in each group after solving problems. Figure 11 shows that in response to question (20), only approximately 55\% of the graduate students (for both introductory and advanced level problems) noted that, after they solve homework problems, they take the time to reflect and learn from the solution. The percentage of faculty members who noted that they take the time to reflect is close to $75 \%$ (for both introductory and graduate-level problem solving) which appears to be lower than expected. Individual discussions suggest that physics faculty felt that they monitor their thought processes while solving the problems. Therefore, reflection at the end of problem solving is not required. In contrast, while solving graduate-level homework problems, some graduate students pointed to the lack of time for why they do not take the time to reflect after solving problems. Following are some explanations from graduate students for their responses:

(i) "If I have enough time, then I would like to reflect and learn from the problem solution after I struggle with it for a long time and then finally solve it successfully."

(ii) "If the solution or the problem is interesting, then I would take time to reflect and learn from it. This usually happens in more challenging problems."

(iii) "To be honest, I didn't do this when I was in college. But now I realized it's helpful."

Only approximately $25 \%$ of introductory physics students noted that they reflect and learn from problem solutions. Since reflection is so important for learning and building a robust knowledge structure, these findings suggest that instructors should consider giving students explicit incentive to reflect after they solve physics problems [18,23-27].

\section{SUMMARY AND CONCLUSION}

We developed and validated the "Attitudes and Approaches to Problem Solving" (AAPS) survey based upon an earlier Attitudes toward problem solving survey by Cummings et al. The survey was administered to physics graduate students, who answered the survey questions about problem solving in their graduate courses and in introductory physics. Their survey responses were compared with those of introductory students in physics and astronomy courses and physics faculty. We discussed the responses individually with some students and faculty and obtained written explanations from some graduate students on selected questions.

There were major differences on some measures in graduate students' responses about problem solving in the graduate courses compared to problem solving in introductory physics. In general, graduate students' responses about problem solving in the graduate courses were less favorable (less expertlike) than their responses about solving introductory physics problems. For example, graduate students were more likely to feel stuck unless they got help while solving graduate-level problems than on introductory-level problems. Similarly, for problem solving in their graduate-level courses, fewer graduate students could tell when their work and/or answer was wrong without talking to someone else but many more could tell when their solution was not correct when solving introductory physics problems. Also, more graduate students noted that they routinely use equations even if they are nonintuitive while solving graduate-level problems than while solving introductory physics problems. In addition, fewer graduate students noted that they enjoy solving challenging graduate-level physics problems than solving challenging introductory physics problems (perhaps 
because introductory physics problems are still easier for them).

Comparison of graduate students' responses with faculty responses suggests that, on several measures, graduate students' responses to AAPS survey are less expertlike than faculty responses. For example, unlike the graduate students, all physics faculty noted that they enjoy solving challenging physics problems. The less favorable response of graduate students while solving graduate-level problems is partly due to the fact that the graduate students are not yet experts, especially in their own graduate course content. Due to lower expertise in solving graduate-level problems, graduate students are more likely to feel stuck unless they get help, not know whether their solution is right or wrong, use equations that are not intuitive and not enjoy solving challenging graduate-level problems on which their grade depends and for which they have a limited time to solve.

We find that, on some survey questions, graduate students' and faculty responses to the survey questions must be interpreted carefully. For example, only two thirds of the faculty noted that they always think about the concepts that underlie the problem explicitly while solving introductorylevel problems, which is lower than the fraction of graduate students who noted that they do so while solving both introductory-level and graduate-level problems. Individual discussions with faculty members suggests that they felt that, after years of teaching experience, the concepts that underlie many of the introductory physics problems have become "automatic" for them and they do not need to explicitly think about them. The fact that in contrast to most faculty, many graduate students always think explicitly about the concepts that underlie the problems both while solving introductory and graduate-level problems, suggests that the graduate students have not developed the same level of expertise and automaticity in solving introductory-level problems as physics faculty have. In fact, question (14) related to this issue is one of those rare questions on the survey for which the faculty responses were significantly different for introductory and graduate-level problem solving (in particular, more than $90 \%$ of the faculty noted that they explicitly think about concepts that underlie the graduate-level problems while solving them).

Comparison of graduate students' AAPS responses with introductory physics students' responses suggests that, on some measures, graduate students have more favorable attitudes and approaches to solving introductory physics problems due to their higher level of expertise than the introductory students. However, on other questions, the responses must be interpreted carefully in light of the explanations provided by the graduate students. For example, in response to whether the problem solving in physics is essentially "plug and chug," the response of the graduate students while solving introductory physics problems and those of introductory physics students is indistinguishable. But discussions and written explanations of graduate students suggest that they have developed sufficient expertise in introductory physics so that solving such problems does not require much explicit thought and they can often immediately tell which principle of physics is applicable in a particular situation. On the other hand, prior research suggests that many introductory physics students jump into implementation of problem solution and immediately look for the formulas without performing a conceptual analysis and planning of the problem solution [28-30].

Also, due to their higher level of expertise, graduate students find introductory physics equations more intuitive and are better able to discern the applicability of a physics principle epitomized in the form of a mathematical equation to diverse situations than the introductory students. In solving both introductory and graduate-level problems, the fraction of graduate students who noted that they reflect and learn from the problem solution after solving a problem is larger than the fraction of introductory physics students who noted doing so in their courses. While we may desire an even higher percentage of graduate students to reflect and learn from their problem solving, written explanations suggest that, in the graduate courses, some students felt they did not have the time to reflect. Also, they often did not reflect on the exam solutions even after they received the solutions because they did not expect those problems to show up again on another exam. Some graduate students explained that the reason they do not reflect after solving an introductory physics problem is that the solutions to those problems are obvious to them and do not require reflection.

There was a large difference between the introductory physics students' and graduate students' responses in their facility to manipulate symbols (vs numbers) with introductory physics students finding it more difficult to solve problems given in symbolic form. In problems where numbers were provided, many introductory students noted that they prefer to plug numbers at the beginning rather than waiting till the end to do so. One suggested strategy to help introductory physics students feel more confident about using symbols is to ask them to underline the variable they are solving for so as to keep it from getting mixed up with the other variables [31]. Developing mathematical facility can also help students develop the confidence to solve the problems symbolically first before substituting values. In addition, instructors can emphasize why it is useful to keep the symbols till the end, including the fact that it can allow them to check the correctness of the solution, e.g., by checking the dimension, and it can also allow them to check the limiting cases which is important for developing confidence in one's solution [31].

In general, the more favorable responses of graduate students on the AAPS survey toward attitudes and approaches to introductory problem solving compared to those of the introductory physics students and less favorable responses compared to the faculty imply that graduate students have a higher level of expertise in introductory physics but less expertise than physics faculty. Moreover, graduate students' responses to graduate-level problem solving in many instances are comparable to introductory students' responses to introductory-level problem solving, implying that the graduate students are still developing expertise in their own graduate-level courses just like introductory students are still developing expertise in introductory physics.

As noted earlier, the survey results also suggest that many graduate students are more likely to enjoy solving difficult introductory physics problems than graduate-level problems, 
they are more likely to feel stuck while solving graduatelevel problems, less likely to find graduate-level equations intuitive (but they still use them freely to solve problems), less likely to predict whether their problem solution is correct and to not give a high priority to reflecting and learning after solving a problem. While one can rationalize these less expertlike responses of graduate students to graduate-level problem solving by claiming that these are reflections of the fact that they are not "experts" in graduate-level courses, they force us to think about whether we are achieving the goals of the graduate courses and giving graduate students an opportunity to learn effective approaches and attitudes to problem solving. Graduate instructors should consider whether assessment in those courses should include both quantitative and conceptual questions to motivate students to reflect on problem solving and give explicit incentive for reflection and for development of intuition about the equations underlying the problems.

\section{ACKNOWLEDGMENTS}

We thank F. Reif, R. Glaser, R. P. Devaty and J. Levy for very useful discussions. We thank Dr. Clement Stone for help with statistical analysis. We are grateful to all the faculty who administered the survey to their class and took the survey for their help.

\section{APPENDIX: AAPS SURVEY QUESTIONNAIRE AND FAVORABLE (EXPERT) RESPONSES}

To what extent do you agree with each of the following statements when you solve physics problems? Answer with a single letter as follows:

(A) Strongly Agree

(B) Agree Somewhat

(C) Neutral or Don't Know

(D) Disagree Somewhat

(E) Strongly Disagree

(1) If I'm not sure about the right way to start a problem, I'm stuck unless I go see the teacher/TA or someone else for help. (D/E)

(2) When solving physics problems, I often make approximations about the physical world. (A/B)

(3) In solving problems in physics, being able to handle the mathematics is the most important part of the process. (D/E)

(4) In solving problems in physics, I always identify the physics principles involved in the problem first before looking for corresponding equations. (A/B)

(5) "Problem solving" in physics basically means matching problems with the correct equations and then substituting values to get a number. (D/E)

(6) In solving problems in physics, I can often tell when my work and/or answer is wrong, even without looking at the answer in the back of the book or talking to someone else about it. (A/B)

(7) To be able to use an equation to solve a problem (particularly in a problem that I haven't seen before), I think about what each term in the equation represents and how it matches the problem situation. (A/B)

(8) There is usually only one correct way to solve a given problem in physics. (D/E)

(9) I use a similar approach to solving all problems involving conservation of linear momentum even if the physical situations given in the problems are very different. (A/B)

(10) If I am not sure about the correct approach to solving a problem, I will reflect upon physics principles that may apply and see if they yield a reasonable solution. (A/B)

(11) Equations are not things that one needs to understand in an intuitive sense; I routinely use equations to calculate numerical answers even if they are nonintuitive. (D/E)

(12) Physics involves many equations each of which applies primarily to a specific situation. (D/E)

(13) If I used two different approaches to solve a physics problem and they gave different answers, I would spend considerable time thinking about which approach is more reasonable. $(\mathrm{A} / \mathrm{B})$

(14) When I solve physics problems, I always explicitly think about the concepts that underlie the problem. (A/B)

(15) When solving physics problems, I often find it useful to first draw a picture or a diagram of the situations described in the problems. $(\mathrm{A} / \mathrm{B})$

(16) When answering conceptual physics questions, I mostly use my "gut" feeling rather than using the physics principles I usually think about when solving quantitative problems. (D/E)

(17) I am equally likely to draw pictures and/or diagrams when answering a multiple-choice question or a corresponding free-response (essay) question. (A/B)

(18) I usually draw pictures and/or diagrams even if there is no partial credit for drawing them. (A/B)

(19) I am equally likely to do scratch work when answering a multiple-choice question or a corresponding freeresponse (essay) question. (A/B)

(20) After I solve each physics homework problem, I take the time to reflect and learn from the problem solution. (A/B)

(21) After I have solved several physics problems in which the same principle is applied in different contexts, I should be able to apply the same principle in other situations. $(\mathrm{A} / \mathrm{B})$

(22) If I obtain an answer to a physics problem that does not seem reasonable, I spend considerable time thinking about what may be wrong with the problem solution. (A/B)

(23) If I cannot solve a physics problem in $10 \mathrm{~min}$, I give up on that problem. (D/E)

(24) When I have difficulty solving a physics homework problem, I like to think through the problem with a peer. (A/B)

(25) When I do not get a question correct on a test or homework, I always make sure I learn from my mistakes and do not make the same mistakes again. (A/B)

(26) It is more useful for me to solve a few difficult problems using a systematic approach and learn from them rather than solving many similar easy problems one after another. $(\mathrm{A} / \mathrm{B})$

(27) I enjoy solving physics problems even though it can be challenging at times. $(\mathrm{A} / \mathrm{B})$

(28) I try different approaches if one approach does not work. (A/B) 
(29) If I realize that my answer to a physics problem is not reasonable, I trace back my solution to see where I went wrong. $(\mathrm{A} / \mathrm{B})$

(30) It is much more difficult to solve a physics problem with symbols than solving an identical problem with a numerical answer. (D/E)

(31) While solving a physics problem with a numerical answer, I prefer to solve the problem symbolically first and only plug in the numbers at the very end. (A/B)

(32) Suppose you are given two problems. One problem is about a block sliding down an inclined plane with no friction present. The other problem is about a person swinging on a rope. Air resistance is negligible. You are told that both problems can be solved using the concept of conservation of mechanical energy of the system. Which one of the following statements do you MOST agree with? (Choose only one answer.) (A/B)

(A) The two problems can be solved using very similar methods.

(B) The two problems can be solved using somewhat similar methods.

(C) The two problems must be solved using somewhat different methods.
(D) The two problems must be solved using very different methods.

(E) There is not enough information given to know how the problems will be solved.

(33) Suppose you are given two problems. One problem is about a block sliding down an inclined plane. There is friction between the block and the incline. The other problem is about a person swinging on a rope. There is air resistance between the person and air molecules. You are told that both problems can be solved using the concept of conservation of total (not just mechanical) energy. Which one of the following statements do you MOST agree with? (Choose only one answer.) $\mathrm{A} / \mathrm{B}$

(A) The two problems can be solved using very similar methods.

(B) The two problems can be solved using somewhat similar methods.

(C) The two problems must be solved using somewhat different methods.

(D) The two problems must be solved using very different methods.

(E) There is not enough information given to know how the problems will be solved.
[1] D. Hammer, Student resources for learning introductory physics, Am. J. Phys. 68, S52 (2000).

[2] M. Schommer, Effects of beliefs about the nature of knowledge on comprehension, J. Educ. Psychol. 82, 498 (1990).

[3] I. Halloun and D. Hestenes, in Interpreting VASS dimensions and profiles Science \& Education, 7(6), 553-577 (1998); I. Halloun, Views about science and physics achievement: The VASS story, 605-613, in The changing role of physics departments in modern universities, edited by E. F. Redish, and J. S. Rigden, Proceedings of ICUPE, (AIP Press, College Park, MD, 1997).

[4] E. F. Redish, J. M. Saul, and R. N. Steinberg, Student Expectations in Introductory Physics, Am. J. Phys. 66, 212 (1998).

[5] W. Adams, K. Perkins, N. Podolefsky, M. Dubson, N. Finkelstein, and C. Wieman, New instrument for measuring student beliefs about physics and learning physics: The Colorado Learning Attitudes about Science Survey, Phys. Rev. ST Phys. Educ. Res. 2, 010101 (2006).

[6] K. Gray, W. Adams, C. Wieman, and K. Perkins, Students know what physicists believe, but they don't agree: A study using CLASS survey, Phys. Rev. ST Phys. Educ. Res. 4, 020106 (2008).

[7] J. Marx and K. Cummings, What factors really influence shifts in students' attitudes and expectations in an introductory physics course?, AIP Conf. Proc. 883, 101 (2007).

[8] E. Elby, Helping physics students learn how to learn, Am. J. Phys. 69, S54 (2001).

[9] P. Laws, Workshop Physics (Wiley, New York, 1999).

[10] K. Cummings, S. Lockwood, and J. D. Marx, Attitudes toward problem solving as predictors of student success, AIP Conf. Proc. 720, 133 (2004).

[11] A. Collins, J. S. Brown, and S. E. Newman, in Knowing,
Learning, and Instruction: Essays in Honor of Robert Glaser, edited by L. B. Resnick (Lawrence Erlbaum, Hillsdale, NJ, 1989), pp. 453-494.

[12] A. Schoenfeld, Mathematical Problem Solving (Academic Press, New York, 1985).

[13] A. Schoenfeld, in Handbook for Research on Mathematics Teaching and Learning, edited by D. Grouws, (McMillan, New York, 1992), Chap. 15, pp. 334-370.

[14] A. Schoenfeld, in Toward the Thinking Curriculum: Current Cognitive Research, edited by L. B. Resnick and B. L. Klopfer (ASCD, Washington, DC, 1989), pp. 83-103.

[15] C. Singh and A. Mason, Physics graduate students' attitudes and approaches to problem solving, AIP Conf. Proc. 1179, 273 (2009).

[16] A. J. Nitko, Educational Assessments of Students, 2nd ed. (Prentice Hall/Merrill, Englewood Cliffs, NJ, 1996); J. C. Nunnally, Psychometric Theory, 2nd ed. (McGraw-Hill, New York, 1978).

[17] J. Cohen, Statistical power analysis for the behavioral sciences, 2nd Edition, (Erlbaum, Hillsdale, NJ, 1989), pp. 83103.

[18] A. Mason and C. Singh, Do advanced physics students learn from their mistakes without explicit intervention?, Am. J. Phys. 78(7) 760-767, (2010).

[19] E. Torigoe, Doctoral dissertation, University of Illinois at Urbana Champaign, 2008.

[20] E. Mazur, Peer Instruction: A User's Manual, Prentice-Hall Series in Educational Innovation, (Prentice-Hall, Upper Saddle River, NJ, 1997) and video that goes with the book.

[21] C. Singh, Assessing student expertise in introductory physics with isomorphic problems. II: Effect of some potential factors on problem solving and transfer, Phys. Rev. ST Phys. Educ. 
Res. 4, 010105 (2008).

[22] D. Hestenes, M. Wells, and G. Swackhamer, Force Concept Inventory, Phys. Teach. 30, 141 (1992).

[23] P. Black and D. Wiliam, Inside the black box: Raising standards through classroom assessment, Phi Delta Kappan 80, 139 (1998).

[24] P. Black and D. Wiliam, Assessment and classroom learning, Assess. Educ. 5, 7 (1998).

[25] E. Yerushalmi, C. Singh, and B. Eylon, Physics learning in the context of scaffolded diagnostic tasks (I): The experimental setup, AIP Conf. Proc. 951, 27 (2007).

[26] C. Singh, E. Yerushalmi, and Bat Sheva Eylon, Physics Learning in the context of scaffolded diagnostic tasks (II): The pre- liminary results, AIP Conf. Proc. 951, 31 (2007).

[27] A. Mason and C. Singh, Helping students learn effective problem solving strategies by reflecting with peers, Am. J. Phys. 78, 748 (2010).

[28] F. Reif, Scientific approaches to science education, Phys. Today 39(11), 48 (1986).

[29] F. Reif, Millikan Lecture 1994: Understanding and teaching important scientific thought processes, Am. J. Phys. 63, 17 (1995).

[30] J. H. Larkin and F. Reif, Understanding and teaching problem solving in physics, Eur. J. Sci. Educ. 1, 191 (1979).

[31] F. Reif, Understanding Basic Mechanics, ISBN 978-0-47111624-0 (Wiley, New York, 1995). 